\title{
Relative Comprehensiveness of Performance Measurement System: Organisational Ownership Structure and Size
}

\author{
Zarinah Abdul Rasit ${ }^{1} \&$ Che Ruhana Isa ${ }^{2}$ \\ ${ }^{1}$ Faculty of Accountancy, Universiti Teknologi MARA, Malaysia \\ ${ }^{2}$ Department of Accountancy, Faculty of Business and Accountancy, University of Malaya, Malaysia \\ Correspondence: Zarinah Abdul Rasit, Faculty of Accountancy, Universiti Teknologi MARA, Malaysia.
}

Received: April 20, 2019

Accepted: May 7, 2019

Online Published: May 19, 2019

doi:10.5430/ijfr.v10n3p380

URL: https://doi.org/10.5430/ijfr.v10n3p380

\begin{abstract}
Change in the business environment has resulted in significant implication in the use of Management Control System (MCS) particularly Performance Measurement System (PMS). Strategic Performance Measurement System (SPMS) has been widely used by organisation to monitor the implementation, achievement and improvement of its plan objectives. Considerable prior research identified inconsistent findings in the relationship between PMS and organisational performance. In view of the fact that organisational culture would significantly being influenced by ownership structure, this research will further explore the comprehensiveness of PMS, the extent to which the systems provide information and integration with strategy and value chain, with different ownership structure. Data were gathered in two (2) phases; firstly, using the survey data administered to the 120 strategic business unit (SBU) managers of the manufacturing companies, members of the Federation of Malaysian Manufacturers (FMM). The second phase involves conducting semi-structured interviews with SBU managers of the 10 companies with foreign and local ownership structure. Findings from the research identified that more comprehensive PMS is being implemented by foreign owned companies rather than local own companies. The size of the companies may also influence the PMS comprehensiveness. The PMS implementation was also found to be influenced by the parent companies. Adequate information technology (IT) plays an important role for effective use of the PMS, provide added supports for performance assessment, communication and exchange of information within the organisation and inter-organisations worldwide. Findings provide significant insights into the organisational factors influence the PMS design.
\end{abstract}

Keywords: management control system, organisational ownership structure, organisational size, performance measurement system

\section{Introduction}

Changes in technology, shortened product lifecycle and innovation in production processes have significant implications on the use of Management Accounting Systems (MAS) in particular Performance Measurement System (PMS). Traditional or short-term financial measures are no longer adequate to provide required information essential for managers' decision making. The system was claimed to suffer from lack of comprehensiveness, imprecise in evaluating performance, limited focus on long-term performance and too much focus on short-term performance (Ittner and Larcker (1998). Management Control System (MCS) is viewed as a broader term that encompasses MAS and management accounting (MA) (Chenhall, 2003). According to Henri (2006), PMS is one component of MCS. PMS has evolved from a system which consists of a few measures focus on financial measures to a system consisting of multiple non-financial and financial measures (Kaplan and Norton, 1996). The review on the development of PMS suggests changes are required and the more comprehensive PMS are being implemented to suit with the needs of the current business environment.

The literature also suggests that more comprehensive PMS has distinct feature which is described to include not only the incorporation balanced concept of financial and non-financial measures but also the integration of firm's strategy into the system (Chenhall, 2005; Henri, 2006; Franco-Santos, Lucianetti \& Bourne, 2012; Guenther \& Heinicke, 2018). Past researches examining the link between PMS and organisational performance seem to provide ambiguous and contradictory findings (Abdul Rasit and Ismail, 2012; Abdul Rasit and Isa, 2015; Chenhall, 2005, Micheli and Manzoni, 2009; Ittner and Larker, 2003; Guenther \& Heinicke, 2018; Davis and Albright, 2004; Hoque and James, 
2000; Said, HassabElnaby and Wier, 2003; Van der Stede, Chow and Lin, 2006).

Promient examples of PMS include techniques such as BSC (Kaplan \& Norton, 1996), Tableau de board (Epstein \& Manzoni, 1998) and performance hierarchies (Lynch \& Cross, 1991; Hall. 2008; Guenther \& Heinicke, 2018; Michael,Justina \& Olabode 2018). The terms Balanced scorecard (BSC), Strategic performance measurement system (SPMS) and Comprehensive performance measurement system (CPMS) are being used interchangeably in prior research (Santos et al., 2012; Hall, 2008; Burney and Widenner, 2007; Cheng, Luckett and Mahama, 2007; Ittner et al., 2003). Based on the review of literature, most scholars define comprehensive PMS in terms of their features (Santos, Lucianetti and Bourne, 2012). BSC is a widely known SPMS (White, 2008) and is considered as comprehensive PMS (Malina \& Selto, 2001; Ittner et al., 2003b; Ullrich \& Tuttle, 2004; Marangoz, 2018).

According to Burney and Matherly (2007), SPMS is different from traditional PMS, as traditional PMS emphasises financial measures of performance whereas SPMS combines both financial and non-financial measures that are chosen through a filtering process to represent organisational strategy. Hence, SPMS permits an organisation to communicate information regarding its long-term strategy, the relations among the various organisational strategic objectives and the link between strategic goals and the employees' actions (Santos et al., 2012; Burney \& Matherly, 2007; Ittner \& Larcker, 1998). Comprehensiveness or contemporary performance measurement system is defined as a system that translate strategy, combine financial, strategic and operational measures (Hall, 2008; Burney and Widenner, 2007; Cheng, Luckett and Mahama, 2007; Ittner et al., 2003).

Prior research asserted that one of the reasons for the ambiguous results is related to the PMS design (Edrikat, Guenther \& Titus, 2018; Guenther \& Heinicke, 2018). Performance measurement system design was also identified to be influenced by organisational context such as organisational structure (Lee \& Yang, 2010), size (Guenther \& Heinicke, 2018) organisational profile, organisational culture, organisational strategy and technology (Ong \& Teh, 2008; Marangoz \& Var 2018). In order to gain further insight of the PMS implementation in the context of Malaysian Manufacturing firms, this research will fill in the gap to provide empirical evidence examining the PMS design in terms of comprehensiveness of PMS implemented among the firms and to identify if the comprehensiveness is influenced by the organisational context particularly ownership structure and company size. This study utilises definition of CPMS as defined by Hall (2008) that focus on informational aspects of PMS. In this research, the PMS comprehensiveness focuses on the extent of the system in providing information and integration of the system with strategy and value chain (Chenhall, 2005; Hall, 2008).

Align with the claim by Otley (2016) regarding the narrow view of questionnaire responses, besides quantitative data, the current research includes an exploratory research to provide qualitative PMS data to further enhance the understanding of the factor influence PMS implementation among Malaysian manufacturing firms. Otley (2016) asserted the need to replace the narrow view of questionnaire data with more tailored approach in the context of specific organization as the choice of PMS is organization-dependent (Looy \& Shafagatova, 2016; Mikail \& Zainol 2018). The remainder of this paper is organized as follows: The next section presents the review of literature, conceptual framework and hypothesis development followed by research methodology, discussion of survey results and interview results. Finally, the paper ends with conclusion and suggestions for future research.

\section{Review of Literature}

Research conducted in Malaysia identified a few factors influence the implementation of PMS includes competitive strategies (Jusoh and Parnell, 2008; Jusoh, Ibrahim and Zainuddin, 2006). Their research provides evidence of association between strategies and PMS (Jusoh et al., 2006; Jusoh and Parnell, 2008; Jusoh, 2008). Prospector strategy was identified to enhance performance with the use of non-financial performance measure (Jusoh et al., 2006). Jusoh (2008) also found higher emphasis on using financial performance measures by firms than non-financial measures. Another PMS research conducted in Malaysia was on Electrical and Electronic firms, firms size, year of establishments and ownership structure were identified to influence PMS use and design (Burgess, Ond and Shaw, 2007). Traditional PMS was found to be implemented by most medium-sized, local-owned and new to moderately established companies (Ong and Teh, 2008).

Research in the area of PMS was conducted in Malaysia by Burgess et al. (2007) which gathered survey data from 149 electrical and electronic firms and members of The Electrical and Electronic Association of Malaysia (TEEAM). Based on the result, more comprehensive PMS or contemporary PMS was found to dominate the sample. The prevalence of more comprehensive PMS was found greater in the larger companies, older organisations and firms with a higher degree of foreign ownership. Using cluster analysis, the result shows that the two distinct features of PMS related to the design and its use are contemporary and traditional PMS. Based on the result, the contemporary PMS was characterised to reflect comprehensiveness in covering future needs, coordinating departments and 
incorporating strategic objectives. The results also indicate a balanced approach of the PMS is described to be comprehensive, provide extensive coverage and balanced measures.

Ong and Teh (2008) examined the factors influencing the design and use of PMS. The factor analysis is conducted to determine whether organisational contextual factors: organisational profile, organisational culture, organisational strategy and technology have influence on PMS. The research findings indicate organisational culture with a high level of learning and knowledge has influence on firms' PMS. Technology is another contextual variable that has significant influence on the firms' PMS. Additionally, consistent with prior research, the cluster analysis indicates most of the companies implementing more comprehensive PMS or contemporary PMS are large in size, foreign-owned and newly-established. On the other hand, less comprehensive PMS or traditional PMS are mostly medium-sized, local-owned and new to moderately established companies. The chi-square results indicate significant difference between the two groups in terms of company size and ownership types but not for company age.

Thus, based on these literatures, the following hypotheses are being proposed:

H1: There is a significant difference in the comprehensiveness of the PMS between companies with different type of ownership structure

$\mathrm{H} 2$ : There is a significant difference in the comprehensiveness of the PMS between companies with different organisational size

The theoretical framework for this study is developed based on the contingency theory which is based on the premise that there is no universally appropriate accounting system which applies equally to organization in all circumstances. Instead, the optimal course of action is contingent (dependent) upon the internal and external situation (Nik Mohd Rashid, Abdul Rasit, Abd Hamid and Yazid, 2017; Otley, 1980). Research examined the implementation of PMS from the contingency theory perspective is still relevant and significant in prior studies (Lee \& Yang, 2011; Guenther \& Heinicke, 2018).

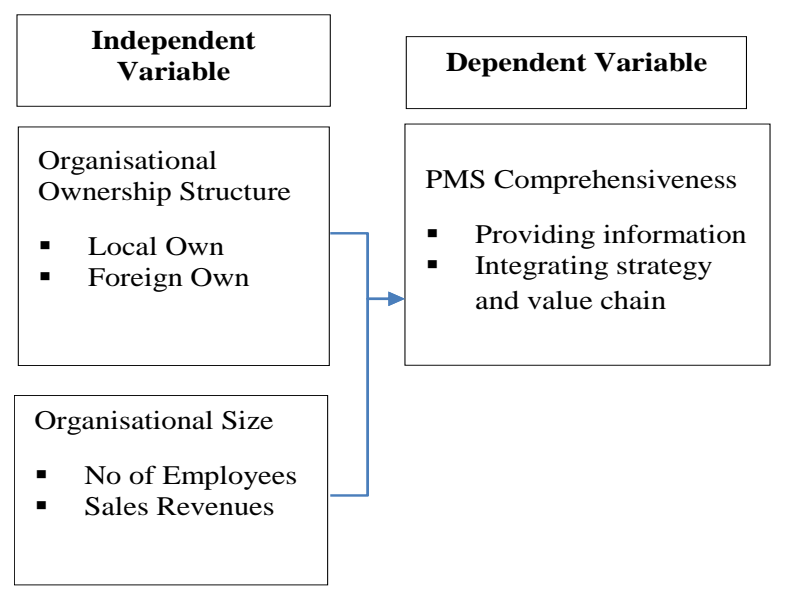

Figure 1. Conceptual framework presents the relation between organisational ownership structure, size and PMS comprehensiveness

\section{Research Methodology}

This research adopts mixed method as data were gathered using both questionnaire survey and semi-structured interviews. This method has a useful purpose to maximise the strengths and minimise the weaknesses of qualitative and quantitative research strategies. This method is regarded as more practical and applicable in conducting a study in social sciences rather than employing a single approach (Bahari, 2010). The first phase of data collection was using questionnaire surveys administered to the business unit managers of the Malaysian manufacturing organizations. According to Burney and Swanson (2010) survey methods allowed information to be collected directly from individuals who use the PMS, thus enhancing external validity of the results (Brownell, Smith, McNellis and Lenk, 1995). In 2011, a total of 600 questionnaires were mailed out to managers of companies with more than 150 number of employees selected through random sampling from the Federation of Malaysian Manufacturer (FMM) directory 2011. Out of the 600 questionnaires distributed, only 120 questionnaires are returned and useable yielding a response rate of 
$20 \%$. T-test analysis is used for hypothesis testing in this study. In the second phase, the semi-structured interviews were conducted to obtain further insights and understanding into the hypothesised relationship. The assumptions to normality and reliability have been addressed in this study.

\subsection{Survey Instrument}

Instrument developed by Hall (2008) captures better representative of PMS comprehensiveness. This instrument was claimed able to pick up strategic linkages of a Balance Scorecard (BSC) in real or in practice which is sufficient to represent the actual condition of BSC usage (Hall, 2008). The instrument consists of 9 items. 5 items represent the extent to which PMS provides performance information related to important parts of SBU operations. The other 4 items were adopted from Chenhall (2005) to measure the extent to which measures integrate with strategy and value chain. Response-bias analysis shows no significant difference between the means indicating non-response bias does not appear to be problematic and can be ignored in the present study.

\subsection{Semi-structured Interviews}

The purpose of conducting the interview is to obtain further explanation on the research findings from the quantitative data analysis. For the interview, respondents are selected from those managers who have previously participated in completing and returning back the questionnaires. Out of 120 survey responses completed and returned, 36 respondents stated in the survey their willingness to be interviewed. In this study, a non-probability sampling method, purposive sampling or judgmental sampling is adopted to select the participants (Marshall, 1996). Purposeful sampling is a dominant strategy in qualitative research, as the technique can be used to seek more information and for in-depth study (Hoepfl, 1997). Hence, in this study, ten managers were chosen to be the participants of the interview. Selection of the participant is based on their willingness to participate, their current work position (middle or top management level) and the location of their firms.

\section{Results and Discussions}

\subsection{Result From Questionnaire Survey}

The profile of firms is as presented in Table 1 . The proportion of locally owned and foreign owned firm is almost equal, $47 \%$ and $48 \%$ respectively.

Table 1. Profile of sample firms

\begin{tabular}{|c|c|c|c|}
\hline Demographic variables & Categories & Frequency & Percent \\
\hline \multirow[t]{9}{*}{ Industry Category } & $\begin{array}{l}\text { Electrical and electronics machinery and } \\
\text { appliances }\end{array}$ & 20 & 16.7 \\
\hline & Food, beverage and tobacco & 22 & 18.3 \\
\hline & Textiles, clothing and footwear & 2 & 1.7 \\
\hline & Transport and automotive & 8 & 6.7 \\
\hline & $\begin{array}{l}\text { Wood and timber products/Furniture } \\
\text { manufacturing }\end{array}$ & 7 & 5.8 \\
\hline & Chemical, gas and petroleum & 23 & 19.2 \\
\hline & Metallurgical or metal goods & 16 & 13.3 \\
\hline & Others & 21 & 17.5 \\
\hline & No information & 1 & 0.8 \\
\hline \multirow[t]{3}{*}{ Ownership structure } & Local (>50\% local equity) & 56 & 46.7 \\
\hline & $\begin{array}{l}\text { Joint-venture (50\% local and 50\% foreign } \\
\text { equity) }\end{array}$ & 7 & 5 \\
\hline & Foreign ( $>50 \%$ foreign equity) & 57 & 48.3 \\
\hline
\end{tabular}




\subsection{Descriptive Statistics and Preliminary Analysis}

Table 2 presents a descriptive statistic of the managers' general perception on the comprehensiveness of PMS (CPMS) implemented in their firm. The results show that the observed means for CPMS lies a little above the theoretical means. The observed mean for CPMS is 5.12 indicating more comprehensive PMS.

Table 2. Descriptive statistics of the main variable $(n=120)$

\begin{tabular}{|c|c|c|c|c|c|c|c|}
\hline \multirow[t]{2}{*}{ Variable } & \multirow[t]{2}{*}{ Mean } & \multirow[t]{2}{*}{ Median } & \multirow{2}{*}{$\begin{array}{l}\text { Standard } \\
\text { Deviation }\end{array}$} & \multicolumn{2}{|c|}{ Actual Range } & \multicolumn{2}{|c|}{ Theoretical Range } \\
\hline & & & & Min & Max & Min & Max \\
\hline CPMS & 5.12 & 5.11 & 0.91 & 1.78 & 7.00 & 1.00 & 7.00 \\
\hline
\end{tabular}

Note: CPMS = comprehensive PMS

\subsection{Data Analysis Results}

Based on the descriptive analysis result in Table 3, the PMS used by the manufacturing companies is comprehensive, which is shown by the overall mean of PMS use, 5.13 and 5.10. Additionally, these mean values also signify that Malaysian manufacturing firms mostly use PMS as a tool to implement strategy and integrate measure used with strategy and value chain. As shown in Table 3, overall mean score for the first use of PMS is 5.13, is higher than 5.10 the overall mean score for the use of PMS for providing performance information. This is consistent with Malmi (2001), who found firms that use CPMS such as BSC at the business unit level, mainly use the PMS for two purposes: as a tool to implement strategy, and for pure information systems. For the first use of PMS, the result also signifies that the PMS is comprehensive, whereby the system is shown to be formal as it is being documented and used for performance evaluation purposes with the highest mean score of 5.30. The PMS provides a link between the business unit activities and organisational objectives, with mean of 5.27. The mean is moderate, 4.88 , for the measure to provide an indication of how business unit activities would have an effect on other business units. For the use of PMS as an information system, the PMS is perceived to be comprehensive, as the system provides broad measures showing important areas of the business unit operations and the mean for this characteristic is 5.20.

Table 3. Descriptive statistics for CPMS

\begin{tabular}{|c|c|c|c|c|c|c|}
\hline \multirow[t]{2}{*}{ Code } & \multirow[t]{2}{*}{ Variables } & \multirow[t]{2}{*}{ Mean } & \multicolumn{2}{|c|}{$\begin{array}{l}\text { Actual } \\
\text { range }\end{array}$} & \multicolumn{2}{|c|}{$\begin{array}{l}\text { Theoretical } \\
\text { range }\end{array}$} \\
\hline & & & Min & Max & Min & Max \\
\hline \multicolumn{7}{|c|}{ Measure integrates with strategy and value chain } \\
\hline CPMS2 & $\begin{array}{l}\text { The performance measurement system is produced in a } \\
\text { fully documented form, which provides a record for } \\
\text { evaluating performance }\end{array}$ & 5.30 & 2.00 & 7.00 & 1.00 & 7.00 \\
\hline CPMS4 & $\begin{array}{l}\text { It provides consistent and mutually reinforcing links } \\
\text { between the current operating performance of your } \\
\text { business unit and the long-term strategies of the } \\
\text { organization }\end{array}$ & 5.08 & 1.00 & 7.00 & 1.00 & 7.00 \\
\hline CPMS6 & $\begin{array}{l}\text { It links together the activities of your business unit to the } \\
\text { achievement of the goals and objectives of the organization }\end{array}$ & 5.27 & 1.00 & 7.00 & 1.00 & 7.00 \\
\hline CPMS8 & $\begin{array}{l}\text { It shows how the activities of your business unit affect the } \\
\text { activities of other units within the organization }\end{array}$ & 4.88 & 1.00 & 7.00 & 1.00 & 7.00 \\
\hline Overall & & 5.13 & 2.50 & 7.00 & 1.00 & 7.00 \\
\hline \multicolumn{7}{|c|}{ Measure provides performance information related to important part of BU operations } \\
\hline CPMS1 & $\begin{array}{l}\text { The performance measurement system provides a broad } \\
\text { range of performance information about different areas of } \\
\text { the business unit }\end{array}$ & 5.11 & 2.00 & 7.00 & 1.00 & 7.00 \\
\hline CPMS3 & $\begin{array}{l}\text { It provides a diverse set of measures related to the key } \\
\text { performance areas of the business unit }\end{array}$ & 5.12 & 1.00 & 7.00 & 1.00 & 7.00 \\
\hline
\end{tabular}




\begin{tabular}{llllllc}
\hline CPMS5 & $\begin{array}{l}\text { The performance measurement system provides } \\
\text { information on different dimensions of the business unit's } \\
\text { performance }\end{array}$ & & 1.92 & 7.00 & 1.00 & 7.00 \\
\hline CPMS7 & $\begin{array}{l}\text { It provides a variety of information about important aspects } \\
\text { of the business unit's operations }\end{array}$ & 5.13 & 1.00 & 7.00 & 1.00 & 7.00 \\
\hline CPMS9 & $\begin{array}{l}\text { The performance measurement system provides a range of } \\
\text { measures that cover the critical areas of the business unit's } \\
\text { operations }\end{array}$ & 5.20 & 1.00 & 7.00 & 1.00 & 7.00 \\
\hline Overall & & 5.10 & 1.20 & 7.00 & 1.00 & 7.00 \\
\hline
\end{tabular}

\subsection{T-Test Analysis}

In this study, T-Test was conducted to determine the difference in the comprehensiveness of PMS (CPMSMEAN) between ownership structure (local, foreign and joint venture), number of employees ( $=<450$ and $>450$ ), sales revenue $(=<\mathrm{RM} 100 \mathrm{~m}$ and $>\mathrm{RM} 100 \mathrm{~m})$. T-test is a technique used to assess the statistical significance of the difference between two samples or group means for a single dependent variables (Hair, Black, Babin and Anderson, 2010; Malhotra, 2010).

Table 4. T-Test results

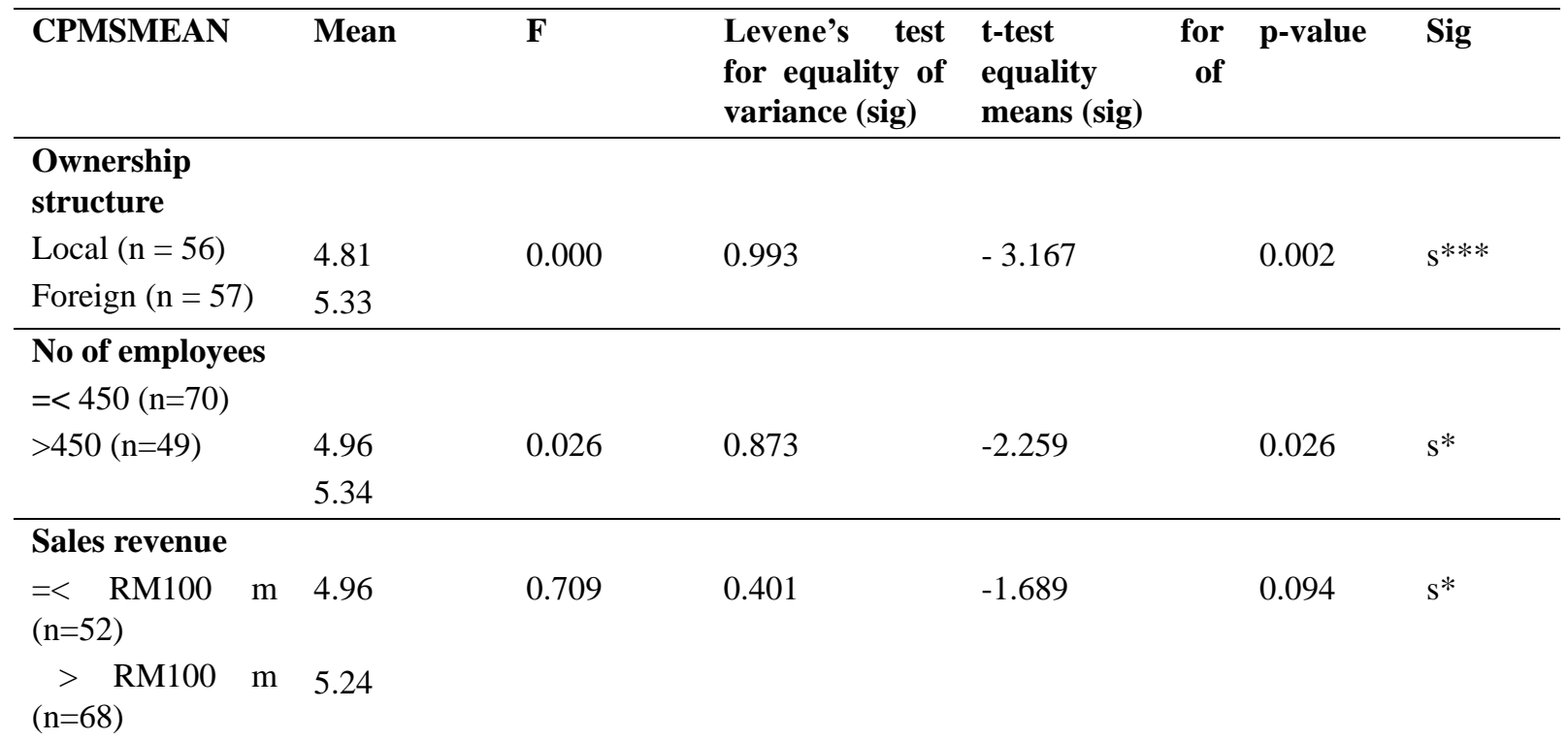

Note: CPMS = comprehensive PMS

*** The mean difference is significant at the 0.01 level.

** The mean difference is significant at the 0.05 level.

* The mean difference is significant at the 0.10 level.

\subsection{Ownership Structure}

T-test analysis was also conducted to identify the difference in the mean of CPMS between the two types of ownership structure. Furthermore, the group sizes are almost equal with 56 locally-owned companies and 57 foreign companies. As shown in Table 4 above, the p-value for CPMSMEAN is significant at 0.002 which is less than the $1 \%$ significant level. Hence, hypothesis 1 is supported. This result signifies that there is significant difference in the comprehensiveness of PMS implemented between locally-owned companies and foreign-owned companies. This finding is consistent with prior empirical study in a Malaysian context, which identified that organisational ownership is associated with traditional and balanced or contemporary PMS (Burgess et al., 2007; Ong and The, 2008; Mokgari \& Pwaka 2018). Their studies conclude that locally-owned companies are more likely to rely on less comprehensive PMS, more traditional and financially-oriented PMS. Whereas foreign-owned companies such as Japanese or Western rely 
more on balanced PMS, thus their PMS is more comprehensive. Since such countries are developed countries, typically, the foreign-owned companies tend to adopt more innovative CPMS. Companies that venture abroad are normally successful and would also incline to promote more innovative approach and implement more comprehensive PMS (Ong and Teh, 2008).

\subsubsection{Number of Employees}

The result of the T-test is reported in Table 4. The data indicates that there are differences in the means for CPMSMEAN between the two groups with t-statistic value -2.259 . The $\mathrm{p}$-values are also significant at $5 \%$ significant level 0.026 for CPMSMEAN. The CPMSMEAN for firms with number of employee more than 450 is 5.34, indicating more comprehensive PMS. In contrast, firms with number of employees < 450 shows a mean value of 4.96 , showing these firms implement less comprehensive PMS. According to Hoque and James (2000) organisation size can be measured using sales turnover, total assets and number of employees. Thus, the results of this study suggest that companies with number of employees more than 450 are large companies which adopt more comprehensive PMS. The more comprehensive the PMS adopted by the firm, the more it can provide relevant information to the managers that can reduce their role ambiguity (Burney and Swanson, 2010; Hall, 2008).

\subsubsection{Sales Revenue}

Following the analysis between groups based on the measures of firm size, number of employees and total assets (Hoque and James, 2000; Momodu, Joshua \& Nma 2018), a t-test analysis was also performed between the main variables and the two (groups) of sales revenue. The sales revenue was categorised into firms with total sales revenue equal and less than RM100 million (=< RM100 million) and sales revenue more than RM100 million (> RM100 million) as indicated in Table 4 above. Consistent to prior analysis results for the number of employees, results also indicate significant variations between groups for the value of CPMSMEAN. In other words, there are significant differences in the value of mean for CPMS between the two categories of firms. The result of the t-test indicates that firms with sales revenue more than RM100 million have more comprehensive PMS than firms with lower sales revenue. According to the mean scores of the CPMSMEAN, the mean is higher for the firm with higher sales revenue. The result implies that firms with larger total sales revenue are large firms that would implement more comprehensive PMS. On the other hand, the CPMSMEAN is lower for firms with lower sales revenue, indicating smaller firms implement less comprehensive PMS. Based on the t-test analyses on the number of employees and the sales revenue, the results provide support for hypothesis 2. The result is consistent with findings by Ahmad and Zabri (2016) who also identified the contingent factor, company size which is measured by number of employees and annual sales has significant relationship with more comprehensive PMS, the non-financial measures implemented by Malaysian manufacturing companies.

\section{Results From Interview}

The second phase of the data collection process was to conduct semi-structured interviews to obtain further insights and understanding of the PMS implementation.

Table 5. Background of the semi-structured interview respondents

\begin{tabular}{llll}
\hline Interviewee & Position & $\begin{array}{l}\text { Work experience } \\
\text { (Years) }\end{array}$ & Ownership Structure \\
\hline 1 & Senior General Manager & 6 & Local \\
\hline 2 & Manufacturing Manager & 4 & Foreign (US and Germany) \\
\hline 3 & Production Manager & 11 & Foreign (Japan) \\
\hline 5 & Production Manager & 20 & Local \\
\hline 6 & Production Manager & 18 & Foreign (Japan) \\
\hline 7 & General Manager of & 10 & Foreign (Hong Kong) \\
\hline 8 & Production & & Foreign (Singapore) \\
\hline 9 & Assistant General Manager & 4 & Local \\
\hline 10 & Assistant General Manager & 4 & Foreign (US) \\
\hline
\end{tabular}




\subsection{Profile of the Semi-structured Interview Participant}

Table 5 presents the background of the interviewees. Four of the interviewees hold top management positions, while six hold middle management positions. All of the managers have at least four years of experience working with their company, and the majority of them have been working for the same company for more than ten years. Their long duration of service and position in their firms indicated that they are knowledgeable with the operations, systems and procedures implemented in their firms.

\subsection{Comprehensive PMS}

Only four interviewees claimed that their firms have comprehensive PMS. When the respondents were asked what they consider as a comprehensive PMS, each interviewee had their own definition of comprehensive PMS. For Interviewee 1, comprehensive PMS is regarded as a well-discussed and agreed PMS with all the stakeholders. Interviewee 2 indicates comprehensive PMS is a measurement system that is applicable to the company's needs, which need not be too detailed and measures should not be too many, as the system should be simple and achievable by individuals. According to him, unachievable targets or KPI can result in a negative impact for people or will become a demoralization factor. Interviewee 3 defined comprehensive PMS as a clear and well- communicated PMS that can provide sufficient feedback to employees. Comprehensive PMS is defined by Interviewee 4 as a requirement for everybody to commit and review consistently every quarter, at all levels and the system should include detail elements or measures.

For Interviewee 5, comprehensiveness is perceived as a system that is fair to everybody; it takes considerably longer time to develop a comprehensive system. According to him, the longer the system is being implemented, through continuous improvement, will help the firm to build CPMS. This is also agreed by Interviewee 6 who argued that PMS will never be comprehensive, as the business environment is so dynamic and is subjected to a lot of uncertainty or ambiguities. As such, PMS need to be dynamic as well. He says that, "I don't think any PMS can be comprehensive. It has to be continuous improvement and updated year by year. There is always something that can affect business operation or business need. PMS is supposed to define everything clearly to manage performance; it can give you feel about what is happening on the floor, business and people".

For Interviewee 9 and Interviewee 8, the term comprehensiveness is related to how the system can provide clear directions, target and motivation to the employees of the organisation. Additionally, a brief definition given by Interviewee 9, "comprehensive PMS is a measurement system that encompasses various aims of the organisation and influences the performance of an individual and motivates individual to achieve targets". CPMS is also perceived as a system that provides clear direction to the organisation community. According to Interviewee 8 , "Comprehensive PMS provides you vision, mission and strategic objectives as organisation needs strategic direction to steer everybody on the same pace to head towards certain objectives or to steer the business to where we want the business to be".

Based on the interview, there are a few definitions given by the interviewees to described the term 'comprehensive PMS'. Overall, CPMS is described by the managers as a PMS that is well-discussed and agreed by all stakeholders, clear and achievable, provides sufficient feedback, provides fair evaluation, is continuously improved and updated, provide an individual employee with clear \& strategic direction and motivation (Franco and Bourne, 2003).

\subsection{Implementation of PMS in Malaysia}

Based on the interviews conducted, nine out of ten of the interviewees assert that the PMS implemented in their companies is formal and established system; however, the system implemented is not fully online and it is not yet an integrated system. Data are recorded and kept in a standard format, which is developed in an Excel program in which the report will only be generated and printed as and when required. Even though the respondents claimed to have established systems, most of the companies are yet to have an automated and online PMS system.

Interviewee 5(Foreign owned) describes the PMS of the company as formal in a sense that there is a PMS guide book used for performance appraisal or evaluation, "The PMS implemented in the company is very formal and we even have a guide book and also evaluation guide criteria. The system that we have now is continuously being improved in two years bases". Additionally, the interviewee has also indicated that the implementation of PMS is being influenced by the parent company. In addition, quality standard awards also require firms to prepare comprehensive self-assessment data which can be obtained from the measurement system data. This is based on the claim made by Interviewee 2(Foreign owned), a manufacturing manager, "It is quite an established PMS system for ABC as it is one of the requirements for ISO and under a group of company in the worldwide so we have to go in line with that strategy".

Interviewees 4(Local owned) and 5(Foreign owned) indicate that their companies have already planned to have an automated PMS and will have the PMS to be online in which reports can be automatically generated from the online 
system soon. Automated or online PMS is when the performance data can be keyed in by manager into the scorecards and then the system can automatically aggregate the data to the higher-level scorecard to show the whole performance of the company. Out of ten interviewees, only these two interviewees indicated that their firms are going to have an automated PMS soon this year. Another three interviewees say that their firms have already automated and integrated PMS, whereas seven of them still have manual PMS.

Interviewee 6(Foreign owned) is one of the three respondents who claimed that his firm has a structured PMS and the automated system which allows managers to distribute and analyse reports easily, "Structured PMS means what needs to be covered in the PMS, how many percentages of the measures which will be financial-based and how many percentages will be non-financial based. The PMS is automated in a sense that it is online and web-based. The system can be assessed anytime, we call it intranet, we can share a lot of things because operation in 42 countries, we can share among senior managers, we do communicate a lot and for people work under us they can always log in the intranet and check what is their appraisal and ratings. Only supervisor and above that can get access to the intranet. Automated PMS is like a living document as the information in the system can continuously being updated and can be assessed by individual employees at any time".

Almost all respondents claimed that the implementation of PMS is at various levels in the firm which includes group, organisational or corporate, business unit level (also called as functional and departmental level) and individual level. The system is somehow identified to be unique among the companies. Overall, all of the respondents interviewed have their PMS to be divided into executive and non-executive level. As mentioned by Interviewee 2(Foreign owned), "The use of PMS is implemented at various hierarchical levels in the company, which includes organisational or corporate level, business unit level, departmental level and individual level. However, at individual level, the key performance indicators (KPI) are applicable to the department head only. For the individual level, the PMS is different between the executive group and the non-executive group. The format of the PMS at individual level is the same for all individuals in the executive groups which consist of the top management, middle management and the lower management. The non-executive group would have a simpler PMS and normally the measures are based on attendance, volume etc".

Similarly, as mentioned by Interviewee 3(Foreign owned), the ITL (Individual Team List) is applicable for all the executive levels and manager levels only. According to Interviewee 4(local owned), "PMS is divided into two groups consisting of executive/all level and non-executive (supervisors and operators). For the non-executive level, the PMS is very direct, such as measures related to completion of work, number of jobs done, attendance and contribution to the company".

All of these companies claimed to have formal and established PMS in place. Regardless of the system used by the companies, all of these companies use KPI to assess their performance. For Interviewee 6(Foreign owned), the General Manager of Production, claimed that his firm has three types of PMS for three employee group levels, "The PMS is in three types; for the operators, supervisors and senior supervisor and managers above": he had also mentioned that, "The only supervisors are not evaluated upon is business acumen (business development, business growth) and it is very much operational KPI".

Based on the earlier part of the interview, in general most of the interviewees indicate that their firms have a PMS that is established, formal and structured i.e. interviewee $2,3,5 \& 6$ are foreign owned companies. Interviewee $5 \& 6$ also claimed to have automated PMS. The implementation of PMS is also at various levels from the organisation level down to the individual level. A few of them, i.e. interviewee 5 (foreign owned company) had also claimed that the implementation of PMS is somehow being influenced by the parent company and assessment requirement related to the firm's quality award. Overall, findings indicate foreign owned companies have more comprehensive that is described to be formal, established, structured and automated PMS. Based on the interview, adequate information technology (IT) plays a role for the effective use of the PMS. IT technology supports better performance assessment, communication and exchange of information within the organisation and inter-organisations worldwide. This is consistent with Franco and Bourne (2003) that organisations are better able to manage through measures with an adequate information technology infrastructure which can provide easy data collection, analysis and interpretation process. Franco and Bourne (2003) also found that having a structured approach to the PMS facilitates its management and daily use. Nudurupati, Tebboune and Hardman (2016) asserted that in this digital era performance measurement has to be more dynamic and more resilient. The measurement system should incorporate evaluation of performance over a wider network covering various stakeholders. Additionally, technological developments plays an important role to create competitive advantage through strategies and relevant measures.

\subsection{The Use of PMS}

All of the respondents interviewed have all the four balanced scorecard perspectives in their scorecard, which includes 
financial performance, customer relations, internal business processes and the organisation's learning and innovation activities. Most of the interviewees claim that the measures derived in their firm's PMS or scorecards are derived from strategy and also from cause-and-effect relationships. According to Interviewee 2, a manufacturing manager, measures derived are subject to the level of management and department head will determine the measures of the department, "As I am the department head for manufacturing, so I will decide the KPI for my team. I have to make them agree with the KPI. In addition, I will also have to ensure the goal is in line with the organisation KPI. Depending on the level, my level is to look into revenue, factors that drive the revenue; product quality (cost that has direct impact on the product) and productivity (cost effective output)".

All of the interviewees are of the opinion that PMS at business unit level has a direct link with the system at individual level, thus individual level performance will result in business unit success. Even though each interviewee claimed the balanced performance measure perspectives were used in their firm's scorecard, each departmental scorecard in the firm has a different weight age for each part. Interviewee 5 made such claims, "We are using measures based on financial, learning, business process and customer. We are using the four in our departmental scorecard, in term of individual, not the same that we will cover, sometimes weight age change. At the departmental level, the total four perspectives are all in the departmental or business unit PMS. From this level, it will be cascaded down to individual target with different weight age as well. Normally, higher weight age will be on critical area of the company and smaller weight age on minor one".

In terms of the content of the PMS of the company, most of the firms interviewed have all the four balanced scorecard perspectives in their PMS. The non-financial measures are extensively used by the companies. This is consistent with findings by Ahmad and Zabri (2016) who identified extensive use of non-financial measures particularly internal processes and customers performance measures by Malaysian manufacturing companies. From the interview findings, the scorecard also consists of balanced financial and non-financial measures at the business unit level,. However, the weight age for each type of perspectives in the scorecard is different at the departmental levels, depending on the focus of the department, i.e. production department focus on internal efficiency.

\section{Conclusion and Future Research}

The study is expected to have both theoretical implications and practical relevance. Theoretically this research will contribute to the existing literature on MAS, particularly, PMS design. Incorporating contingency theory into the research, findings contribute to provide empirical evidence of how the ownership structure would influence the design of PMS implemented by Malaysian manufacturing companies. Prior research had focused on the PMS design in terms of traditional versus contemporary PMS such as research by Burgess et al. (2007). Practically, current research provides further insight into the design of PMS relevant to the comprehensiveness of PMS between companies with different organisational structure and size. Additionally, the comprehensiveness of PMS is for the two (2) purposes; PMS being used as measure integrates with strategy and value chain and measure to provide performance information related to important part of BU operations. This research employs mixed method which gathered both types of data, qualitative and quantitative data to provide extensive information relating to the PMS implementation among the local and foreign owned companies. Future research may further examine behavioural implication of PMS between companies with different organisational structure and size for effective use of PMS to enhance organisational performance.

\section{Acknowledgement}

We wish to thank the Institute of Quality and Knowledge Advancement and the Institute of Research Management and Innovation for their support in funding this project.

\section{References}

Abdul Rasit, Z., \& Isa, C. R. (2015). Decision Facilitating Role of Comprehensive Performance Measurement System (CPMS) and Job Performance: Influence of Role Ambiguity and Locus of Control. Pertanika Journal of Social Sciences and Humanities, 23, 145-160.

Abdul Rasit, Z., \& Ismail, K. (2012). Behavioural consequences of the performance measurement system (PMS) in a decision-facilitating role - a review. Journal of Accounting Perspectives, 5, 35-47.

Ahmad, K., \& Zabri, S. M. (2016). The application of non-financial performance measurement in Malaysian manufacturing firms. Procedia Economics and Finance, 35, 476-484. https://doi.org/10.1016/S2212-5671(16)00059-9

Bahari, S. F. (2010). Qualitative versus quantitative research strategies: contrasting epistemological and ontological 
assumptions. Jurnal Teknologi (Sains Sosial), (52), 17-28. https://doi.org/10.11113/jt.v52.134

Brownell, M. T., Smith, S. W., McNellis, J., \& Lenk, L. (1994-1995). Career decisions in special education: Current and former teachers' personal views. Exceptionality, 5(2), 83-102. https://doi.org/10.1207/s15327035ex0502_3

Burgess, T. F., Ong, T. S., \& Shaw, N. E. (2007). Traditional or Contemporary? The prevalence of performance measurement system types. International Journal of Productivity and Performance Management, 56(7), 583-602. https://doi.org/10.1108/17410400710823633

Burney, L., \& Swanson, N. (2010). The Relationship Between Balanced Scorecard Characteristics and Managers' Job Satisfaction. Journal of Managerial Issues, 22(2), 166.

Cheng, M. M., Luckett, P. F., \& Mahama, H. (2007). Effect of perceived conflict among multiple performance goals and goal difficulty on task performance. Accounting and Finance, 47(2), 221-242. https://doi.org/10.1111/j.1467-629X.2007.00215.x

Chenhall, R. H. (2003). Management control systems design within its organisational context: findings from contingency-based research and directions for the future. Accounting, Organizations and Society, 28(2-3), 127-168. https://doi.org/10.1016/S0361-3682(01)00027-7

Chenhall, R. H. (2005). Integrative strategic performance measurement systems, strategic alignment of manufacturing, learning and strategic outcomes: an exploratory study. Accounting, Organizations and Society, 30(5), 395-422. https://doi.org/10.1016/j.aos.2004.08.001

Davis, S., \& Albright, T. (2004). An investigation of the effect of Balanced Scorecard implementation on financial performance. Management Accounting Research, 15(2), 135-153. https://doi.org/10.1016/j.mar.2003.11.001

Endrikat, J., Guenther, T. W., \& Titus, R. (2018). A Meta-analysis of the Perfromance Effects of Contemporary Performance Measurement Systems. Working paper, TU Dresden.

Franco, M., \& Bourne, M. (2003). Factors that play a role in "managing through measures". Management Decision, 41(8), 698-710. https://doi.org/10.1108/00251740310496215

Franco-Santos, M., Lucianetti, L., \& Bourne, M. (2012). Contemporary performance measurement systems: A review of their consequences and a framework for research. Management Accounting Research, 23(2), 79-119. https://doi.org/10.1016/j.mar.2012.04.001

Guenther, T. W., \& Heinicke, A. (2019, March). Relationships among types of use, levels of sophistication, and organizational outcomes of performance measurement systems: The crucial role of design choices. Management Accounting Research, 42, 1-25. https://doi.org/10.1016/j.mar.2018.07.002

Hair, J., Black, W. C., Babin, B. J., \& Anderson, R. E. (2010). Multivariate data analysis (7th ed.). Upper saddle River, New Jersey: Pearson Education International.

Hall, M. (2008). The effect of comprehensive performance measurement systems on role clarity, psychological empowerment and managerial performance. Accounting, Organizations and Society, 33(2-3), 141-163. https://doi.org/10.1016/j.aos.2007.02.004

Henri, J.-F. (2006). Organisational culture and performance measurement systems. Accounting, Organizations and Society, 31(1), 77-103. https://doi.org/10.1016/j.aos.2004.10.003

Hoepfl, M. C. (1997). Choosing qualitative research: A primer for technology education researchers. Journal of Technology Education, 9(1), 47-63. https://doi.org/10.21061/jte.v9i1.a.4

Hoque, Z., \& James, W. (2000). Linking Balanced Scorecard Measures to Size and Market Factors: Impact on Organisational Performance. (cover story). Journal of Management Accounting Research, 12, 1-17. https://doi.org/10.2308/jmar.2000.12.1.1

Ittner, C. D., \& Larcker, D. F. (1998). Innovations in performance measurement: Trends and research implications. Journal of Management Accounting Research, 10, 205.

Ittner, C. D., \& Larcker, D. F. (2003). Coming Up Short on Nonfinancial Performance Measurement. Harvard Business Review, 81(11), 88-95.

Jusoh, R. (2008). Environmental Uncertainty, performance, and the mediating role of balanced scorecard measures use: evidence from Malaysia. International Review of Business Research Papers, 4(2), 116-135.

Jusoh, R., \& Parnell, J. A. (2008). Competitive strategy and performance measurement in the Malaysian context. 
Management Decision, 46(1), 5.

Jusoh, R., Ibrahim, D. N., \& Zainuddin, Y. (2006). Assessing the Alignment Between Business Strategy and Use of Multiple Measures Using Interaction Approach. The Business Review.

Kaplan, R. S., \& Norton, D. P. (1996). Using the balanced scorecard as a strategic management system. Harvard Business Review, 74(1), 75-85.

Lee, C. L., \& Yang, H. J. (2011). Organization structure, competition and performance measurement systems and their joint effects on performance. Management Accounting Research, 22(2), 84-104.

Malhotra, N. K. (2010). Marketing Research: An Applied Orientation (6th ed.). Upper Saddle River, NJ: Prentice Hall, Inc.

Malmi, T. (2001). Balanced scorecards in Finnish companies: A research note. Management Accounting Research, 12(2), 207-220. https://doi.org/10.1006/mare.2000.0154

Marangoz, I. (2018). The Determination of the Relationship between Somatotypes and Speed of Sub-Elite Athletes. Asian Journal of Education and Training, 4(3), 220-223. https://doi.org/10.20448/journal.522.2018.43.220.223

Marangoz, I., \& Var, S. M. (2018). The Relationship among Somatotype Structures, Body Compositions and Estimated Oxygen Capacities of Elite Male Handball Players. Asian Journal of Education and Training, 4(3), 216-219. https://doi.org/10.20448/journal.522.2018.43.216.219

Marshall, T. F. (1996). The evolution of restorative justice in britain. European Journal on Criminal Policy and Research, 4(4), 21-43. https://doi.org/10.1007/BF02736712

Michael, O., Justina, O., \& Olabode, D. (2018). Child Labour and Protection: An Exploration of Vulnerable Children in Lagos State, Nigeria. Humanities and Social Sciences Letters, 6(4), 171-179.

Micheli, P., \& Manzoni, J.-F. (2009). Strategic Performance Measurement: Benefits, Limitations and Paradoxes. Long Range Planning, In Press, Corrected Proof. https://doi.org/10.1016/j.lrp.2009.12.004

Mikail, A., \& Zainol, Z. A. (2018). Conservation of Biodiversity in Sub Sahara Africa: Prospecting for Genetic Resources and Traditional Knowledge Regulation in Ethiopia. International Journal of Asian Social Science, 8(9), 725-734. https://doi.org/10.18488/journal.1.2018.88.560.568

Mokgari, M. T., \& Pwaka, O. (2018). An Evaluation of Effectiveness of Oversight Committees: A Case of City of Johannesburg, Section 79 Committees. International Journal of Public Policy and Administration Research, 5(2), 48-67. https://doi.org/10.18488/journal.74.2018.52.48.67

Momodu, A. L. I. U., Joshua, O., \& Nma, M. (2018). Audit Fees and Audit Quality: A Study of Listed Companies in the Downstream Sector of Nigerian Petroleum Industry. Humanities and Social Sciences Letters, 6(2), 59-73.

Nik Mohd Rashid, N. M. N, Abdul Rasit, Z, Abdul Hamid, N., \& Yazid, A. S. (2017). Management Accounting Systems (MAS) Adoption: Empirical Evidence from Malaysian Manufacturing Companies. World Applied Sciences Journal, 35(9), 1907-1917.

Nudurupati, S. S., Tebboune, S., \& Hardman, J. (2016). Contemporary performance measurement and management (PMM) in digital economies. Production Planning \& Control, 27(3), 226-235.

Ong, T. O., \& Teh, B. H. (2008). Factor Influencing the design and use of performance measurement systems in the Malaysian electrical and electronics industry. International Journal of Economics and Management, 2(2), 437-457.

Otley, D. (2016). The contingency theory of management accounting and control: 1980-2014. Management Accounting Research, 31, 45-62. https://doi.org/10.1016/j.mar.2016.02.001

Otley, D. T. (1980). The Contingency Theory of Management Accounting Achievement and Prognosis. Accounting, Organizations and Society, 5(4), 413-428. https://doi.org/10.1016/0361-3682(80)90040-9

Said, A. A., Hassab Elnaby, H. R., \& Wier, B. (2003). An Empirical Investigation of the Performance Consequences of Nonfinancial Measures. Journal of Management Accounting Research, 15, 193-223.

Van der Stede, W. A., Chow, C. W., \& Lin, T. W. (2006). Strategy, Choice of Performance Measures, and Performance. Behavioral Research in Accounting, 18, 185-205. https://doi.org/10.2308/bria.2006.18.1.185

Van Looy, A., \& Shafagatova, A. (2016). Business process performance measurement: a structured literature review of indicators, measures and metrics. Springer Plus, 5(1), 1797. https://doi.org/10.1186/s40064-016-3498-1 